\title{
Impact of International Centers on Plant Breeding Training
}

\author{
Gurdev S. Khush ${ }^{1}$ \\ University of California, Davis, CA 95616
}

International agricultural research centers (IARCs) sponsored by the Consultative Group on International Agricultural Research (CGIAR) have been in the forefront of training plant breeders. Out of 15 IARCs, 9 have major responsibility for crop improvement. All of these centers are located in the developing countries with a mandate for improvement of specific crops (Table 1).

Remaining centers are the International Plant Genetic Resource Institute, Rome, Italy (IPGRI), the International Center for Living Aquatic Resources Management, Penang, Malaysia(ICLARM), the InternationalFood Policy Research Institute, Washington, D.C. (IFPRI), the International Water Management Institute, Kandy, Sri Lanka (IWMI), the International Livestock Research Institute, Nairobi, Kenya (ILRI) and the Center for International Forestry Research, Bogar, Indonesia (CIFOR).

CGIAR centers are nonprofit, apolitical, international organizations for science based agricultural development. The centers are autonomous entities supported by more than 50 governments, foundations and development banks. CGIAR's goal is to develop increased public goods for food security, livelihood resilience, poverty reduction, and sustainable management of production systems. One of the important thrusts is human resource capacity building and knowledge dissemination. This is achieved through following training activities:

- Higher degree training (MSc and $\mathrm{PhD}$ level) especially scientists from the national agricultural research and extension systems (NARES) who are exposed to international standards of agricultural research so that they can step into research positions in their countries.

- Train NARES scientists in both public and private sector in specific scientific and communication skills for field and laboratory applications and present their findings in appropriate fora.

- Expose farmers, nongovernmental organization (NGO), and civil society organization (CSO) partners to practical skills through farmer field days.

- Disseminate customized knowledge for primary users and to farming communities using information and communication technologies.

\section{PLANT BREEDING TRAINING IN CGIAR CENTERS}

Crop based CGIAR centers have placed major emphasis on training plant breeders from the inception of their programs. The following types of training programs have been implemented (Table 2).

${ }^{1}$ Retired from the International Rice Research Institute, Los Baños, Philippines, and adjunct professor.
Long-term in-service training. Field technicians and researchers from developing countries were trained for at least 6 months (one full crop season). In a few cases this was preceded by 2 to 3 months of intensive English-learning programs to enable trainees from non-English speaking countries-especially from Francophone countries - to enhance skills in comprehension, speaking, reading, and writing. The research itself would start from planning offield experiments, field preparation, field layout, sowing, and managing the trials throughout the crop season. During the crop season, trainees were taught how to record observations and data on various traits and also manage weeds, pests, and diseases. Lectures on agronomy, soils, physiology, pathology, and entomology were given to enhance the basic knowledge and understanding. Lectures on genetics and plant breeding, hands-on practice on choosing parents for hybridization, raising $\mathrm{F}_{1}$ hybrids and evaluation of segregating populations, and yield evaluation of elite lines formed integral part of the program. Participants were also taught statistics and experimental designs. They learnt recording postharvest data, tabulation, and statistical analysis of trial data. Each participant was asked to prepare a report of the research conducted and present the results to the group. Overall, the participants were given training needed to make them practical plant breeders. This type of training was more emphasized during 1960s, 1970s, and 1980s when there was paucity of trained plant breeders in developing countries.

Short-term in-service training. This program is similar to the above except the participants come for training in specific aspects of plant breeding, such as techniques of hybridization or hybrid seed production or to learn specific skills such as techniques of grain quality analysis. This type of training lasts for 4 to 12 weeks and the trainees work with scientists in respective areas of specialization. There is no rule on the number of trainees, and

Table 1. International agricultural research centers (IARCs) sponsored by the Consultive Group on International Agricultural Research (CGIAR) that have a mandate for crop improvement; CIAT = Centro Internacional de Agricultura Tropical, CIP = Centro Internacional de la Papa, CIMMYT = Centro Internacional de Mejosamiento de Maize y Trigo, ICARDA = International Center for Agricultural Research in Dry Areas, ICRAF $=$ International Center for Research in Agroforestry, ICRISAT $=$ International Crops Research Institute for Semiarid Tropics, IITA = International Institute for Tropical Agriculture, IRRI = International Rice Research Institute, WARDA = West African Rice Development Association.

\begin{tabular}{lll}
\hline Center & Location & Mandate crops \\
\hline CIAT & Cali, Columbia & Global: beans, Cassava, pastures \\
& & Regional: rice (for Latin America) \\
CIP & Lima, Peru & Global: potatoes and sweetpotatoes \\
CIMMYT & El Batan, Mexico & Global: wheat and corn \\
ICARDA & Aleppo, Syria & Global: lentil, barley, faba beans \\
& & Regional: chickpea, forage legumes, wheat \\
ICRAF & Nairobi, Kenya & Regional: agroforestry \\
ICRISAT & Patancheru, India & Sorghum, Pennisetum, peanuts, chickpea, pigeonpea \\
IITA & Ibadan, Nigeria & Global: cowpea, cassava, soybean, yam \\
& & Regional: maize \\
IRRI & Los Baños, Philippines & Global: rice \\
WARDA & Monrovia, Liberia & Regional: rice (for western Africa) \\
\hline
\end{tabular}

numbers may vary from one to a few. These

Training courses. The centers organize training courses on specific topics depending on the demand from NARES partners. Variable number of participants is selected for each course. The courses run for a fixed duration. Center scientists serve as resource speakers and are asked to do laboratory, greenhouse and field work. Some of the courses components are similar to in-service long-term training. Some of the courses offered at IRRI are listed in Table 3. As an example a genetic evaluaand utilization course (GEU) was taugh breeders were trained in techniques of crop improvement.

Degree training. All the IARCs have had training programs leading to master's or doctorate degrees. Since centers are not degree awarding institutions these programs are impleented in cooperation with universities eithe in the IARC host country or universities in the countries of candidates. The candidates register for the degree program and take course work at the university and conduct thesis research under the supervision of one of the center scientists. example degree candidates register and take course work at the nearby University of the Philippines and conduct thesis research under the supervision of an IRRI scientist. The degree pines. IRRI scientists have been appointed as affiliate faculty members of the University of student advisory committee. Students may also register in a university in their own country and come to IRRI for thesis research after completing the course work. A degree is awarded by the university. In such cases, a memorandum of understanding is prepared to implement the joint degree program between the center and the university. Many scientists types of programs are still active. 
Table 2. Types of training programs in plant breeding in Consultive Group on International Agricultural Research (CGIAR) centers.

In service training: long-term

In service training: short term

Training courses on specific topics

$\mathrm{MSc}$ and $\mathrm{PhD}$ degree training

Postdoctoral training

Apprentices

from developing countries have been trained at the degree level by all the IARCs and many of them hold senior positions in the agricultural research organizations and universities in their respective countries. Several serve as staff members of IARCs.

Postdoctoral training. Young PhDs from developing countries and a few from developed countries are awarded postdoctoral fellowships and work with center scientists for 2 to 3 years. This enhances their scientific horizon and they contribute to center research programs. Sometimes midlevel scientists come to centers for short-term (6 months) or long-term ( 1 to 2 years) assignments and are classified as international fellows or visiting scientists.

Apprentices. Students from developed and developing countries often visit ICRISAT for short periods, mostly during the summer, to conduct short-term projects including data analysis, report writing, and technical training. The goal is to give the students experience in international centers.

\section{PRESENT STATUS OF PLANT BREEDING TRAINING IN IARCS}

About 60 to 70 international plant breeders work in IARCs and have the responsibility for training plant breeders. Thousands of plant breeders have been trained at IARCs. The exact number of those trained at ICRISAT, for example, is given in Table 4.

Throughout 1960 s to 1980 s funds for training came from the core budget of centers. However, from the 1990s onward, core support for centers has declined and more and more center research is funded through bilateral projects. Trainees are primarily supported from bilateral grant funds. These projects generally have a training component. Thus, postdoctoral and degree candidates are supported from such funds. This has resulted in an increase of degree and postdoctoral training (Table 5) and reduction in in-service training.

In contrast to core support for training during 1970s and 1980s most of the support for training now comes from bilateral donors (Table 6).

\section{FUTURE OF PLANT BREEDING TRAINING IN IARCs}

As mentioned above, the support for IARCs has declined over the years, and the number of plant breeders on center staff has also declined. This has resulted in reduced capacity for training. As a result of shift in nature of funding, postdoctoral and degree students are now being trained in molecular and cellular techniques and little or no exposure to field oriented training. This trend needs to be reversed. Only way to do so would be to restore

core support for training in CGIAR centers. The future plant breeders must be trained in conventional methods of crop improvement as well as modern techniques of molecular marker applications in plant breeding. They should also be cognizant of potentials of genetic engineering applications and aware of societal perceptions about the food products produced from genetically modified organisms.

Table 3. Examples of training courses offered at the International Rice Research Institute (IRRI).

\begin{tabular}{lcc}
\hline Course & Years offered & Participants trained (no.) \\
\hline Genetic Evaluation and Utilization & $1975-87$ & 439 \\
Genetic Resource Conservation and Management & $1985,1988,1989$ & 28 \\
Database Management for Genetic Resources & 1988 & 9 \\
G × E Interaction & $1995,1997,2000,2001$ & 28 \\
AFLP Analysis for Rice Improvement & 1996 & 4 \\
Hybrid Rice Breeding & $1996-99$ & 35 \\
Hybrid Rice Seed Production & $1991-98$ & 95 \\
International Rice Information System & 2002 & 17 \\
Molecular Markers in Rice Breeding & 2001 & 14 \\
Plant Breeding & 2002,2005 & 38 \\
Advances in Marker Assisted Breeding & 2005 & 18 \\
\hline
\end{tabular}

Table 4. Number of crop improvement training program participants at International Crops Research Institute for Semiarid Tropics (ICRISAT) during 1974-2004.

\begin{tabular}{lcrr}
\hline & \multicolumn{2}{c}{ Particpants (no.) } \\
\cline { 2 - 4 } Category & Female & Male & Total \\
\hline In-service (long-term) & 106 & 869 & 975 \\
In-service (Short-term) & 45 & 227 & 272 \\
Research fellows & 118 & 552 & 670 \\
MSc and PhD scholars & 69 & 134 & 203 \\
Postdoctoral fellows & 11 & 49 & 60 \\
Apprentices & 89 & 76 & 165 \\
Total & 438 & 1907 & 2345 \\
\hline
\end{tabular}

Table 5. PhD students and postdoctoral scientists at four Consultive Group on International Agricultural Research (CGIAR) centers during 2005; IRRI = International Rice Research Institute, CIMMYT = Centro Internacional de Mejosamiento de Maize y Trigo, ICARDA = International Center for Agricultural Research in Dry Areas, ICRISAT = International Crops Research Institute for Semiarid Tropics.

\begin{tabular}{lcccr}
\hline Degree & IRRI & CIMMYT & ICARDA & ICRISAT \\
\hline MSc & 8 & 9 & 6 & 4 \\
PhD & 20 & 16 & 5 & 36 \\
Postdoctoral & 6 & 9 & 3 & 5 \\
\hline
\end{tabular}

Table 6. Some of the bilateral donors for plant preeding training in Consultive Group on International Agricultural Research (CGIAR) centers.

\begin{tabular}{ll}
\hline Initials & Bilateral donors \\
\hline ACIAR & Australian Center for International Agricultural Research \\
ADB & Asian Development Bank \\
AUSAID & Australian Agency for International Development \\
BMZ & German Federal Ministry for Economic Cooperation and Development \\
CIDA & Canadian International Development Agency \\
DFID & Department for International Development, UK \\
FAO & Food and Agricultural Organization of United Nations \\
IAEA & International Atomic Energy Agency \\
IFAD & International Fund for Agricultural Development \\
JICA & Japan International Center for Agriculture \\
RF & Rockefeller Foundation \\
SDC & Swiss Agency for Development and Cooperation \\
SIDA & Swedish International Development cooperation Agency \\
USAID & United States Agency for International Development \\
WB & World Bank \\
\hline
\end{tabular}

